\title{
Individualized positive end-expiratory pressure guided by end-expiratory lung volume in early acute respiratory distress syndrome: study protocol for the multicenter, randomized IPERPEEP trial
}

Domenico Luca Grieco ${ }^{1,2^{*}}$, Salvatore Maurizio Maggiore ${ }^{3}$, Giacomo Bellani ${ }^{4,5}$, Savino Spadaro ${ }^{6}$, Elena Spinelli ${ }^{7}$, Tommaso Tonetti ${ }^{8}$, Luca S. Menga ${ }^{1,2}$, Marco Pozzi ${ }^{9}$, Denise Battaglini ${ }^{10,11}$, Rosa Di Mussi ${ }^{12}$, Andrea Bruni ${ }^{13}$, Andrea De Gaetano ${ }^{14}$, Carmine Giovanni lovino ${ }^{3}$, Matteo Brioni ${ }^{7}$, Francesco Mojoli ${ }^{9}$, Giuseppe Foti ${ }^{4,5}$, Carlo Aberto Volta ${ }^{6}$, Paolo Pelosi ${ }^{10,11}$, Paolo Navalesi ${ }^{15,16}$, Salvatore Grasso ${ }^{12}$, V. Marco Ranieri ${ }^{8}$, Massimo Antonelli ${ }^{1,2}$ and the IPERPEEP study group

\begin{abstract}
Background: In acute respiratory distress syndrome (ARDS), response to positive end-expiratory pressure (PEEP) is variable according to different degrees of lung recruitability. The search for a tool to individualize PEEP based on patients' individual response is warranted.

End-expiratory lung volume (EELV) assessment by nitrogen washin-washout aids bedside estimation of PEEPinduced alveolar recruitment and may therefore help titrate PEEP on patient's individual recruitability. We designed a randomized trial to test whether an individualized PEEP setting protocol driven by EELV measurement may improve a composite clinical outcome in patients with moderate-to-severe ARDS (IPERPEEP trial). Methods: IPERPEEP is an open-label, multicenter, randomized trial that will be conducted in 10 intensive care units in Italy and will enroll 132 ARDS patients showing $\mathrm{PaO}_{2} / \mathrm{FiO}_{2}$ ratio $\leq 150 \mathrm{mmHg}$ within $24 \mathrm{~h}$ from endotracheal intubation while on mechanical ventilation with PEEP $5 \mathrm{cmH}_{2} \mathrm{O}$.

To standardize lung volumes at study initiation, all patients will undergo mechanical ventilation with tidal volume of $6 \mathrm{ml} / \mathrm{kg}$ of predicted body weight and PEEP set to obtain a plateau pressure within 28 and $30 \mathrm{cmH}_{2} \mathrm{O}$ for 30 min (EXPRESS PEEP).

Afterwards, a 5-step decremental PEEP trial will be conducted (EXPRESS PEEP to PEEP $5 \mathrm{cmH}_{2} \mathrm{O}$ ), and EELV will be measured at each step. Recruitment-to-inflation ratio will be calculated for each PEEP range from EELV difference.
\end{abstract}

\footnotetext{
* Correspondence: dlgrieco@outlook.it

${ }^{1}$ Department of Emergency, Intensive Care Medicine and Anesthesia,

Fondazione Policlinico Universitario A. Gemelli IRCCS, L.go F. Vito, 00168 Rome, Italy

${ }^{2}$ Istituto di Anestesiologia e Rianimazione, Università Cattolica del Sacro Cuore, L.go F. Vito, 00168 Rome, Italy

Full list of author information is available at the end of the article
}

(c) The Author(s). 2022 Open Access This article is licensed under a Creative Commons Attribution 4.0 International License, which permits use, sharing, adaptation, distribution and reproduction in any medium or format, as long as you give appropriate credit to the original author(s) and the source, provide a link to the Creative Commons licence, and indicate if changes were made. The images or other third party material in this article are included in the article's Creative Commons licence, unless indicated otherwise in a credit line to the material. If material is not included in the article's Creative Commons licence and your intended use is not permitted by statutory regulation or exceeds the permitted use, you will need to obtain permission directly from the copyright holder. To view a copy of this licence, visit http://creativecommons.org/licenses/by/4.0/. The Creative Commons Public Domain Dedication waiver (http://creativecommons.org/publicdomain/zero/1.0/) applies to the data made available in this article, unless otherwise stated in a credit line to the data. 
Patients will be then randomized to receive mechanical ventilation with PEEP set according to the optimal recruitment observed in the PEEP trial (IPERPEEP arm) trial or to achieve a plateau pressure of $28-30 \mathrm{cmH}_{2} \mathrm{O}$ (control arm, EXPRESS strategy). In both groups, tidal volume size, use of prone positioning and neuromuscular blocking agents, and weaning from PEEP and from mechanical ventilation will be standardized.

The primary endpoint of the study is a composite clinical outcome incorporating in-ICU mortality, 60-day ventilatorfree days, and serum interleukin-6 concentration over the course of the initial $72 \mathrm{~h}$ of treatment.

Discussion: The IPERPEEP study is a randomized trial powered to elucidate whether an individualized PEEP setting protocol based on bedside assessment of lung recruitability can improve a composite clinical outcome during moderate-to-severe ARDS.

Trial registration: ClinicalTrials.gov NCT04012073. Registered 9 July 2019.

Keywords: Acute respiratory distress syndrome, Positive end-expiratory pressure, Mechanical ventilation, Ventilatorinduced lung injury

\section{Background}

Mechanical ventilation is the cornerstone treatment of the acute respiratory distress syndrome (ARDS). However, mechanical ventilation can itself initiate and worsen lung damage due to the so-called ventilatorinduced lung injury (VILI), which is an inflammatory response that worsens lung function and contributes to the development of the organ dysfunction observed in ARDS patients [1]. Different strategies have been suggested to attenuate VILI: limiting tidal volume $\left(V_{\mathrm{T}}\right)$; plateau and driving pressure mitigates lung injury and improves clinical outcome [2-6].

Low $V_{\mathrm{T}}$ may generate alveolar derecruitment and worsen oxygenation that can be reversed by the application of a positive end-expiratory pressure (PEEP) [7, 8]. It is widely accepted that PEEP setting should aim to a balance between alveolar recruitment (i.e., re-opening of collapsed alveolar units with increased lung volume available for tidal ventilation) and the damage unavoidably generated in the already open tissue. Hence, over the last decade, great effort has been made to identify the PEEP-setting strategy that balances the need for lung recruitment and PEEP-induced alveolar overdistension; PEEP titration methods based on respiratory system compliance [9-11], oxygenation, shunt value $s[12,13]$, and pressure-volume curve [14] have been proposed. Four different randomized studies comparing higher versus lower PEEP, with high PEEP set according to respiratory system mechanic $s[10]$, oxygenation impairment $[12,13]$ or to maximize respiratory system complianc e[15], failed to detect a benefit. Higher PEEP however yielded a shorter time to successful weaning in the EXPRESS study, especially in most severe patients [10].

Despite a meta-analysis highlighted a survival benefit in more severe patients treated with higher PEE P[16], the most relevant drawback of such "universal" strategies is that lung recruitability has great inter-individual variability, with high PEEP enhancing lung injury in patients with low recruitability and low PEEP not fully exerting its beneficial effects in recruitable patients [14, 17-20]. Thus, a search for a tool to individualize PEEP on patient's individual response appears warranted. In spite of encouraging results coming from a preliminary study [21], neither transpulmonary pressure-guided nor driving pressure-driven PEEP did provide benefits in larger trials $[15,22]$.

Measurement of end-expiratory lung volume (EELV) by the nitrogen washing-washout technique, bedside available from recent ICU ventilators, has been shown to reliably estimate lung aeration and may help mechanistically titrate PEEP on patient's individual response [2325].

We designed an open-label, multicenter, randomized trial to test the safety and feasibility of an individualized PEEP setting protocol driven by EELV and to determine whether this may improve a composite clinical outcome in patients with moderate-to-severe ARDS.

\section{Methods \\ Study design}

IPERPEEP is an investigator-initiated, multicenter, parallel-group, open-label, two-arm, randomized trial that will be conducted on patients with ARDS and $\mathrm{PaO}_{2} / \mathrm{FiO}_{2}$ ratio equal to or lower than $150 \mathrm{mmHg}$. The study will be conducted in 10 intensive care units (ICU) in Italy (please refer to Additional file 1 for the details of involved sites). The first patient will be randomized in late 2020. This protocol conforms to the Consolidated Standards of Reporting Trials (CONSORT) guidelines. Figure 1 shows the Standard Protocol Items: Recommendation for Interventional Trials (SPIRIT) schedule of enrollment, interventions, and assessments. By the time of this submission, the protocol has been approved by the ethics committee of the coordinating center (Fondazione Policlinico A. Gemelli IRCCS, ID 38554/18 and 45307/19). 


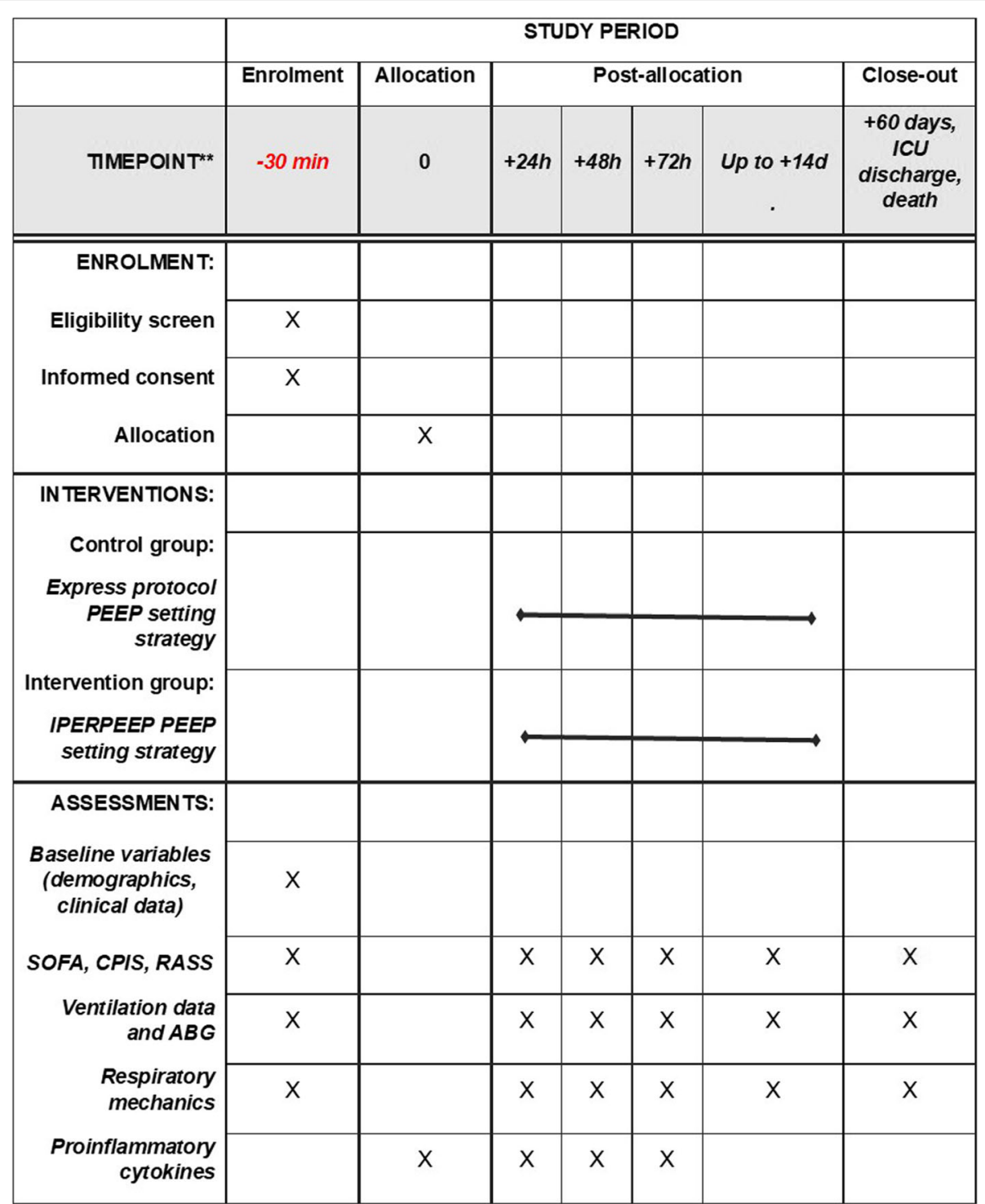

Fig. 1 Standard Protocol Items: Recommendation for Interventional Trials (SPIRIT) schedule of enrollment, interventions, and assessments. SOFA, Sequential Organ Failure Assessment; CPIS, clinical pulmonary index score; RASS, Ramsay Agitation Sedation Scale; ICU, intensive care unit

There was no public nor patients' involvement in the design of the trial.

The study has been registered on clinicaltrials.gov (NCT04012073) on July 9, 2019.

\section{Objectives of the study}

The primary objective of the study is to determine whether a PEEP setting protocol driven by EELV measurement may improve a composite clinical outcome in patients with moderate to severe ARDS, as compared to the EXPRESS protocol [10].

\section{Selection of the participants}

All adult ICU patients requiring invasive mechanical ventilation due to acute hypoxemic respiratory failure will be screened for the enrolment. Patients with ARDS and moderate-to-severe oxygenation impairment $\left(\mathrm{PaO}_{2} / \mathrm{FiO}_{2} \leq\right.$ $150 \mathrm{mmHg}$ while receiving controlled mechanical ventilation with $\mathrm{PEEP}=5 \mathrm{cmH} 2 \mathrm{O}$ ) will be the studied population.

Eligibility inclusion criteria for moderate-to-severe ARDS, according to the Berlin definition, will be assessed within the first $24 \mathrm{~h}$ from the initiation of invasive mechanical ventilation [26]:

1. Acute respiratory failure within 1 week of a known clinical insult or new or worsening respiratory symptoms;

2. Bilateral infiltrates at the chest $\mathrm{x}$-ray or CT scan, not fully explained by effusions, lobar/lung collapse, or nodules; 
3. Respiratory failure not fully explained by cardiac failure or fluid overload; objective assessment required to exclude hydrostatic edema if no risk factor present.

4. $\mathrm{PaO}_{2} / \mathrm{FiO}_{2}$ ratio $\leq 200[27]$.

5. Written informed consent.

Exclusion criteria will be as follows: pregnancy, pneumothorax, acute brain injury, decompensated heart failure (NYHA 3-4 before the acute phase of the disease or documented ejection fraction $<35 \%$ or pulmonary capillary wedge pressure $>18 \mathrm{mmHg}$ ) or acute coronary syndrome, intubation as a result of an acute exacerbation of chronic pulmonary disease, body mass index greater than $35 \mathrm{~kg} / \mathrm{m}^{2}$ or lower than $<35 \mathrm{~kg} / \mathrm{m}^{2}$, any chronic disease requiring long-term oxygen therapy or mechanical ventilation at home, neuromuscular diseases, severe chronic liver disease (Child-Pugh $\mathrm{C}$ or worse), bone marrow transplantation or chemotherapy-induced neutropenia, history of liver or lung transplant, decision to withhold life-sustaining treatment, need for therapy with inhaled nitric oxide due to documented pulmonary arterial hypertension, life-threatening hypoxemia deemed to require extracorporeal membrane oxygenation (ECMO), documented barotrauma, high risk of mortality within 3 months from other than ARDS (severe neurological damage, age $>85$ years and cancer patients in terminal stage of the disease), and persistent hemodynamic instability/intractable shock (norepinephrine $>1 \mathrm{mcg} / \mathrm{kg} / \mathrm{h}$ and $/$ or blood lactate $>5 \mathrm{mmol} / \mathrm{L}$ and/ or considered too hemodynamically unstable for enrolment in the study by the attending physician).

\section{Oxygenation criterion validation}

Each patient meeting inclusion criteria will be evaluated for the presence of the oxygenation criterion. After neuromuscular paralysis and endotracheal suctioning, eligible patients will be ventilated for $30 \mathrm{~min}$ with PEEP $=5 \mathrm{cmH}_{2} \mathrm{O}$ in the semi-recumbent position; afterward, arterial blood gas analysis (ABG) will be performed to compute $\mathrm{PaO}_{2} / \mathrm{FiO}_{2}$ ratio. Patients showing $\mathrm{PaO}_{2} / \mathrm{FiO}_{2} \leq$ $150 \mathrm{mmHg}$ will be enrolled. Patients showing $\mathrm{PaO}_{2} / \mathrm{FiO}_{2}$ $<200$ and $>150 \mathrm{mmHg}$ will be treated according to the standard clinical practice and reassessed for the presence of oxygenation criterion within $24 \mathrm{~h}$ from endotracheal intubation. To limit the exposure to low PEEP of possibly recruitable patients with severe oxygenation impairment, the ABG certifying the oxygenation criterion will be permitted at any time during the 30 -min monitoring period.

\section{Procedures}

After inclusion in the study, all patients will receive continuous neuro-muscular blocking agents (NMBA) infusion for $48 \mathrm{~h}$ and will be connected to a mechanical ventilator equipped with EELV measurement module (Carescape R860, GE Healthcare, USA). A standard bitube low-resistance circuit with a low-dead space, lowresistance, and high-efficiency heat and moisture exchanger or a heated and humidified bi-tube circuit will be used to connect the patient to the ventilator, according to the preference of the attending physician and the practice of each institution. The use of heated and humidified bi-tube circuits (advised settings: humidification chamber temperature set at $37^{\circ} \mathrm{C}$, absolute humidity provided $44 \mathrm{mgH}_{2} \mathrm{O} / \mathrm{L}$ ) will be encouraged in patients that remain hypercapnic $\left(\mathrm{pH}<7.30\right.$ and $\mathrm{PaCO}_{2}>50$ ) despite all ventilator settings provided by the study protocol [28].

A dedicated polyfunctional feeding tube provided with an esophageal balloon (Nutrivent, Sidam, Mirandola (MO), Italy) to monitor esophageal pressure, estimate pleural pressure, and compute transpulmonary pressure will be placed in all enrolled patients after inclusion. The correct placement of the catheter and the adequate filling of the balloon will be confirmed by an occlusion test (airway pressure/esophageal pressure ratio will be recorded: $0.8-1.2$ will be considered acceptable); the occlusion test will be repeated before any measurement is done to ensure the recordings of reliable values $[29,30]$.

A closed endotracheal suctioning system will be preferentially used in all the enrolled patients.

After the enrollment, mechanical ventilator will be set according to the following strategy: $V_{\mathrm{T}}=6 \mathrm{~mL} / \mathrm{kg}$ of predicted body weight; inspiratory flow set at $60 \mathrm{l} / \mathrm{min}$ resulting in an end-inspiratory pause of $0.3-0.5 \mathrm{~s}$; respiratory rate $20-35$ to maintain $\mathrm{pH}>7.30$, PEEP set so that the plateau $\left(P_{\mathrm{PLAT}}\right)$ pressure will be within the following limits: $P_{\text {PLAT }}=28-30 \mathrm{cmH}_{2} \mathrm{O}$ (EXPRESS PEEP), $\mathrm{FiO}_{2}$ set to achieve a $\mathrm{SpO}_{2}>88-95 \%$ and not higher than $90 \%$. In case of hypercapnia with $\mathrm{pH}<7.30$ despite a respiratory rate $=30-35$, an increase in $V_{\mathrm{T}}$ up to $8 \mathrm{ml} /$ $\mathrm{kg}$ will be allowed over the entire course of the study.

Predicted body weight (PBW) will be calculated according to the following formulas [3]:

$$
\begin{aligned}
\text { Males : PBW }(\mathrm{kg})=50 & +0.91 \text { (height in } \mathrm{cm}-152.4) \\
\text { Females : PBW }(\mathrm{kg})= & 45.5 \\
& +0.91 \text { (height in } \mathrm{cm}-152.4)
\end{aligned}
$$

After 30 min with these settings to standardize lung volumes at maximum recruitment, a new ABG will be recorded. Afterwards, a 5-step decremental PEEP trial (EXPRESS PEEP to PEEP 5) will be conducted with the dedicated software on the ventilator (Inview PEEP, GE). Each step will last $8 \mathrm{~min}$, and EELV will be measured with a 0.2 change in the $\mathrm{FiO}_{2}$. In case of evident airway closure $[31,32]$, the minimal PEEP tested in the PEEP 
trial will be the one providing a $\mathrm{PEEP}_{\mathrm{TOT}}=$ airway opening pressure [32].

PEEP-induced lung recruitment across each PEEP step (Rec) will be computed as follows:

$$
\begin{aligned}
\text { Rec }= & \left(\text { EELV }_{\text {PEEPhigh }}-E_{\text {EELV }} \text { PEEPlow }\right)-\left[\left(\text { PEEP }_{\text {high }}-\text { PEEP }_{\text {low }}\right)\right. \\
& \left.\times \text { Compliance }_{\text {PEEPlow }}\right]
\end{aligned}
$$

After the PEEP trial, a one-breath derecruitment maneuver from PEEP 5 to PEEP 0 will be conducted to assess baseline functional residual capacity (FRC) that will be measured as the difference between EELV at PEEP 5 and the lung volume increase above FRC, measured as the difference in expired tidal volume as PEEP is decreased from 5 to $0 \mathrm{cmH}_{2} \mathrm{O}$ in one breath with respiratory rate $\leq 8$ breaths per minute. In particular, the lung volume due to the presence of PEEP 5 (PEEP5 $5_{\text {volume }}$ ) will be measured by subtracting the insufflated $V_{\mathrm{T}}$ from the expired $V_{\mathrm{T}}$ during a 5 -s exhalation (respiratory rate $<8$ ) just after PEEP is reduced from 5 to 0 .

$$
\mathrm{FRC}=\mathrm{EELV}_{\text {PEEP5 }}-\mathrm{PEEP} 5_{\text {volulme }}
$$

This procedure will not be conducted in patients with airway closure.

In particular, when interpreting the results of the PEEP trial, Rec across two adjacent PEEP levels will be normalized to the changes in the effective PEEP (total PEEP) applied: $\mathrm{REC}_{\mathrm{IND}} / \mathrm{cmH}_{2} \mathrm{O}$ will be computed as REC divided by the PEEP difference. For each PEEP range, the recruitment-to-inflation ratio (RI) will be then calculated as previously described $[19,33]$ :

$$
\mathrm{RI}=\mathrm{REC}_{\mathrm{IND}} / \text { Compliance }_{\text {PEEPlow }} \text {. }
$$

Each patient will be then randomized to undergo mechanical ventilation according to the two PEEPsetting protocols described in the next paragraph. Randomization will be stratified according to the volume of effective lung recruitment during the PEEP trial, as described in the "Randomization and record keeping" section.

Patients for whom the measurement of the EELV is not be feasible due to any technical reason will not be randomized and accurately recorded on the screening $\log$.

\section{PEEP setting protocols \\ Control group}

The EXPRESS protocol is as follows [10]: $V_{\mathrm{T}}=6 \mathrm{~mL} / \mathrm{kg}$; inspiratory flow set at $60 \mathrm{l} / \mathrm{min}$ and end-inspiratory pause of $0.2-0.5 \mathrm{sec}$, PEEP set so that $P_{\mathrm{PLAT}}$, measured during the end-inspiratory pause of $1-3 \mathrm{~s}$, will be within the following limits: $28 \mathrm{cmH}_{2} \mathrm{O} \leq P_{\text {PLAT }} \leq 30 \mathrm{cmH}_{2} \mathrm{O}$;. $\mathrm{FiO}_{2}$ set to achieve a $\mathrm{SpO}_{2}>88-95 \%$.
In case of hypercapnia with $\mathrm{pH}<7.30$ despite a respiratory rate $=30-35$, an increase in $V_{\mathrm{T}}$ up to $8 \mathrm{ml} / \mathrm{kg}$ will be allowed.

\section{Intervention group}

Full details of the procedures performed in the intervention group are provided in Fig. 2.

$V_{\mathrm{T}}=6 \mathrm{~mL} / \mathrm{kg}$; inspiratory flow set at $60 \mathrm{l} / \mathrm{min}$ resulting in an end-inspiratory pause of $0.2-0.5 \mathrm{~s}$. Respiratory rate set between 20 and 35 to maintain $\mathrm{pH}>7.30 . \mathrm{FiO}_{2}$ set to achieve a $\mathrm{SpO}_{2}>88-95 \%$.

In case of hypercapnia with $\mathrm{pH}<7.30$ despite a respiratory rate $=30-35$, an increase in VT up to $8 \mathrm{ml} / \mathrm{kg}$ will be allowed.

PEEP will be $\geq 5 \mathrm{cmH}_{2} \mathrm{O}$ and set to ensure the maximum recruitment observed in the PEEP trial, with a maximum permitted $P_{\text {PLAT }}$ of $30 \mathrm{cmH}_{2} \mathrm{O}$.

In particular, when interpreting the results of the PEEP trial, RI across two adjacent PEEP levels will drive PEEP setting.

- $\mathrm{RI} \geq 1.5$ between two PEEP levels will lead to the setting of the higher PEEP.

- $\mathrm{RI}<0.5$ will lead to the setting of the lower PEEP value.

- In case of $\mathrm{RI} \geq 0.5$ and $<1.5$, the choice among two adjacent PEEP levels will be left to the attending physician, who will indicate the set PEEP in order to best balance between the commitment of limiting total, static, and dynamic strain and of optimizing oxygenation and hemodynamics.

Due to possible interferences with EELV measurement, in patients showing airway closure [31, 32, 34], no PEEP lower than the airway opening pressure will be tested or used in the IPERPEEP group for the whole duration of the intervention.

A similar 5-step PEEP trial will re-assess lung response to different levels of PEEP every $12-24 \mathrm{~h}$, in case of changes in the body position or any other clinical events requiring modifications of the ventilatory settings.

Following PEEP trials will be conducted to investigate RI at the five PEEP levels closest to the set one.

Before the procedure, PEEP will be set for $15 \mathrm{~min}$ at the maximum PEEP expected to be tested during the PEEP trial, to ensure that $P_{\text {PLAT }}$ remains below the safety limit with this setting: no $\mathrm{PEEP}<5 \mathrm{cmH} 2 \mathrm{O}$, generating $P_{\text {PLAT }}>30 \mathrm{cmH}_{2} \mathrm{O}$ or lower than the airway opening pressure (in case of airway closure) will be tested or used over the entire course of the study in this intervention group. In particular, each following PEEP trial will investigate response to PEEP at values ranging from +6 and - 6 than the previously set one (i.e., in case of previously set PEEP $=12$, PEEP trial at 6-9-12-15-18; in case of 


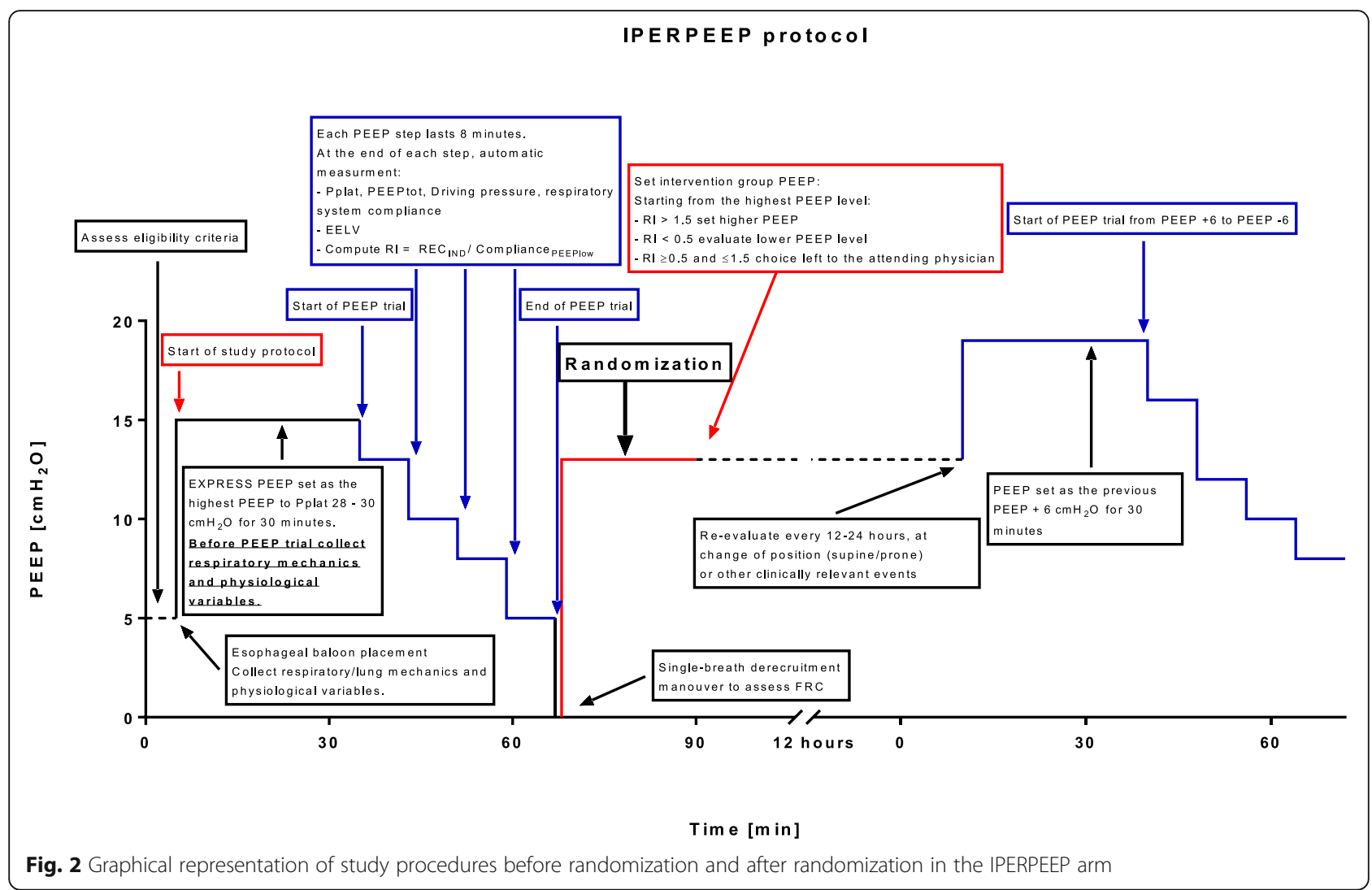

previously set PEEP $=16$, PEEP trial at PEEP $=10-13$ 16-19-22; in case of previously set $\mathrm{PEEP}=8$, PEEP trial at PEEP $=5-8-11-14$ ).

The PEEP level will be then modified according to the strategy described above.

In both groups, the assigned ventilation protocol will be followed for a minimum of $72 \mathrm{~h}$ from randomization and any time fully controlled ventilation is deemed necessary by the attending physician up to 14 days from randomization. After 14 days from randomization, PEEP will be set according to the clinical practice of each institution.

\section{Measurements}

All patients intubated due to hypoxemic respiratory failure and not included will be recorded on a dedicated screening log.

Demographics will be collected at study entry. Physiological variables will be recorded at the moment of enrolment (PEEP 5), after maximum PEEP is set before the PEEP trial, 1-6-12-24-48 $\mathrm{h}$ after randomization, and then on a daily basis up to 60 days or ICU discharge.

Data of the ventilation management (type of ventilation, $\mathrm{FiO}_{2}$, tidal volume, mean airway pressure, PEEP, plateau pressure, minute ventilation, respiratory rate, esophageal end-inspiratory and end-expiratory pressures, static stress, dynamic stress and total stress, proportion of spontaneous ventilation on minute ventilation, $\mathrm{VO}_{2}$, $\mathrm{VCO}_{2}$ ), physiologic data (heart rate, arterial pressure, $\mathrm{SpO}_{2}$, end-tidal $\mathrm{CO}_{2}$ ), and results of the blood gas analyses $\left(\mathrm{pH}, \mathrm{SaO}_{2}, \mathrm{PaO}_{2}, \mathrm{PaCO}_{2}, \mathrm{SvO}_{2}, \mathrm{PvCO}_{2}\right.$, oxygenation index, dead space fraction) will be collected.

Respiratory mechanics will be recorded at the moment of enrolment (PEEP 5), at each step of the first PEEP trial, and 1-6-12-24-48 $\mathrm{h}$ from randomization and then on a daily basis (72-96-120...) up to 60 days or ICU discharge. End-expiratory airway pressure $\left(\mathrm{PEEP}_{\mathrm{AW}}\right)$ and the end-expiratory esophageal pressure $\left(\mathrm{PEEP}_{\mathrm{ES}}\right)$ will be recorded during a 4-s expiratory hold. End-inspiratory airway pressure $\left(P_{p^{2}} t_{\mathrm{AW}}\right)$ and end-inspiratory esophageal pressure (Pplat ${ }_{\mathrm{ES}}$ ) will be measured during a 1-s end inspiratory hold. Expired tidal volume $\left(V_{\mathrm{T}}\right)$ will be measured as the integration of the flow-time curve during expiration.

End-expiratory airway pressure $\left(\mathrm{PEEP}_{\mathrm{AW}}\right)$ and the end-expiratory esophageal pressure $\left(\mathrm{PEEP}_{\mathrm{ES}}\right)$ will be recorded during a 4-s expiratory hold. End-inspiratory airway pressure $\left(P\right.$ plat $\left._{\mathrm{AW}}\right)$ and end-inspiratory esophageal pressure $\left(P\right.$ plat $\left._{\mathrm{ES}}\right)$ will be measured during a 1-s end inspiratory hold. Expired tidal volume $\left(V_{\mathrm{T}}\right)$ will be measured as the integration of the flow-time curve during expiration.

Advanced respiratory mechanics parameters will be computed afterwards. Stress will be calculated any time 
respiratory mechanics is measured, while strain will be measured before randomization in all patients and in the intervention group any time a PEEP trial is repeated; formulas are also shown in Table 1.

The levels of proinflammatory cytokines (tumor necrosis factor [TNF], interleukin 6 [IL-6], and interleukin 8 [IL-8]) will be assessed from serum probes (enzymelinked immunosorbent assay (ELISA)) of all included patients at study inclusion and 24,48 , and $72 \mathrm{~h}$ after randomization.

The following scoring systems will be calculated daily: simplified organ failure assessment score (SOFA), modified clinical pulmonary infection score (CPIS), and Richmond agitation and sedation scale (RASS). These systems and organ failure definitions used for the study purposes are reported in Additional file 2.

\section{Concomitant patient medical management}

Concomitant patients' management, including medical treatments and procedures, is detailed in Additional file 3.

\section{Study endpoints}

The primary endpoint will be a composite clinical outcome that incorporates in-ICU mortality, 60-day ventilation-free days (VFD60), and the area under the curve of the interleukin- 6 serum blood cytokine concentration (IL6AUC) during the first $72 \mathrm{~h}$ of observation.

Secondary endpoints will be as follows: ICU-, 90-day and in hospital mortality, 28 and 60-day ventilation-free days (VFD60), the area under the curve (AUC) of serum blood cytokines concentrations measured as stated in the study protocol; lung static, dynamic and total stress and strain after randomization; airway and lung driving and plateau pressures, compliance, compliance/PBW, dead space fraction, $\mathrm{PaO}_{2} / \mathrm{FiO}_{2}$ ratio, oxygenation stretch index and oxygenation index during the study treatment; and SOFA, CPIS, the incidence of complications or adverse reactions, the frequency and duration of other adjunctive therapeutic measures, transfusion requirements, the daily cumulative doses of analgesic and sedative agents, cumulative catecholamine requirements/ $24 \mathrm{~h}$ throughout the study period, frequency and duration of renal replacement therapy, the number of failing organs, and the "organ-failure-free days" within 28 days after randomization.

\section{Randomization and record keeping}

Patient data, clinical status, laboratory results, and respiratory parameters will be collected on a web-based case report form (Ferrariodati, Italia). Participants will be randomized in a ratio of 1:1. Randomization will be performed by an electronic, web-based centralized, validated system.

Randomization will be stratified according to:

- $\mathrm{RI} \geq 1$ and $<1$ across the range between the lowest and highest PEEP tested during the PEEP trial [23] (see the "Procedures" section for details).

All original records will be archived and secured for 10 years and then destroyed according to the hospital standards concerning destruction of confidential information.

\section{Data monitoring}

Data monitoring will be performed for quality control purposes by an independent company not involved in the study (Clinical Trial Center, Rome, Italy). Amis of

Table 1 Computed respiratory mechanics parameters

\begin{tabular}{|c|c|}
\hline Parameter & Formula \\
\hline Airway driving pressure & $\Delta \mathrm{P}=$ Pplat $_{\mathrm{aw}}-\mathrm{PEEP}$ aw \\
\hline Transpulmonary end-inspiratory pressure & Pplat $_{\mathrm{L}}=$ Plat $_{\mathrm{aw}}-$ Pplat $_{\mathrm{es}}$ \\
\hline Transpulmonary end-expiratory pressure & $P E E P_{L}=P E E P_{a w}-P E E P_{e s}$ \\
\hline Lung driving pressure & $\Delta \mathrm{P}_{\mathrm{L}}=$ Pplat $_{\mathrm{L}}-\mathrm{PEEP}_{\mathrm{L}}$ \\
\hline Lung plateau pressure, elastance-derived & Pplat $_{\mathrm{L}, \mathrm{EL}}=$ Pplat $_{\mathrm{aw}} \times\left(\Delta \mathrm{P}_{\mathrm{L}} / \Delta \mathrm{P}\right)$ \\
\hline Static respiratory system compliance & $\mathrm{Cst}_{\mathrm{RS}}=V_{\mathrm{T}} / \Delta \mathrm{P}$ \\
\hline Static lung compliance & $\mathrm{Cst}_{\mathrm{L}}=V_{\mathrm{T}} / \Delta \mathrm{P}_{\mathrm{L}}$ \\
\hline Static chest wall compliance & $\mathrm{Cst}_{\mathrm{cW}}=V_{\mathrm{T}} /\left(\right.$ Pplat $\left._{\mathrm{es}}-\mathrm{PEEP}_{\mathrm{es}}\right)$ \\
\hline Oxygenation-stretch index & $\mathrm{OSI}=\mathrm{PaO}_{2} /\left(\mathrm{FiO}_{2} \times \Delta \mathrm{P}\right)$ \\
\hline Dynamic strain & Dynamic strain $=V_{T} / F R C_{\text {PEEPset }}$ \\
\hline Static strain (strain due to PEEP) & Static strain $=\left(\right.$ PEEP $_{\text {volume }}-$ ReC ZEEP-PEEP $) / F_{R C_{\text {PEEPset }}}$ \\
\hline Static stress (stress due to PEEP) & Static stress $=P E E P_{a w} \times\left(\Delta P_{L} / \Delta P\right)$ \\
\hline Dynamic stress & Dynamic stress $=$ Pplat $_{a w} \times\left(\Delta \mathrm{P}_{\mathrm{L}} / \Delta \mathrm{P}\right)$ \\
\hline
\end{tabular}


monitoring will be to evaluate the study progress and to verify the accuracy of data recording.

\section{Statistics}

All collected data will be tabulated descriptively by study group and analyzed on an intention-to-treat basis. Comparisons between groups will be performed with the chisquared test or the Fisher's exact test, as appropriate. Ordinal qualitative variables or non-normal quantitative variables will be compared with the Wilcoxon sum of ranks test. Quantitative normal variables will be compared with the Student $t$-test. In particular, analysis of the primary efficacy criterion will be performed with Wilcoxon-Mann-Whitney sum of ranks test.

Consistently to other published studies [22], every participant in the treatment group will be compared with every participant in the control group and assigned a score resulting from each comparison.

Mortality takes precedence over VFD60, which takes precedence over IL6AUC. Two VFD60s will be considered different for the purpose of scoring only if their difference is larger than 5 days. Similarly, two IL6AUC's measurements will be considered different only if their difference exceeds $10 \%$ of the smaller of the two.

These individual-comparison scores are added up to obtain the cumulative score primary endpoint for each participant. Scoring system for the primary endpoint is detailed in Additional file 4.

For the purpose of the study, mechanical ventilation will be defined as: invasive mechanical ventilation with endotracheal tube or tracheostomy and noninvasive positive pressure ventilation, including continuous positive airway pressure. High flow oxygen therapy through nasal cannula or tracheostomy will not be considered as mechanical ventilation.

The assumptions and methodology used for the determination of the sample size are detailed in Additional file 5 [35]. Given the results obtained, and adopting a conservative approach in order to compensate for the small residual random variation in the numerical assessment of the sample size, it appears that a sample size of 56 subjects per arm would be sufficient to obtain $80 \%$ power in detecting a difference in the composite endpoint, at a type 1 error level of 0.05 , two-tail. With an attrition rate of $15 \%$, a total of 132 patients in two equal groups of 66 patients each should be enrolled. This corresponds to a mean of 19 patients per center.

Primary and secondary endpoints will also be analyzed in subgroups, as defined below:

- $\triangle$ EELV5-16/FRC $\geq 73 \%$ [18] during the PEEP trial

- $\triangle$ EELV5-16/FRC $<73 \%[23]$ during the PEEP trial

- $\mathrm{RI} \geq 1$ and $<1$ across the range between the lowest and highest PEEP tested during the PEEP trial
- $\mathrm{P} / \mathrm{F}$ ratio $<100 \mathrm{mmHg}$ at study inclusion

- $\mathrm{IL}-6>400 \mathrm{pg} / \mathrm{ml}$ at study inclusion

All analyses will be performed at a 0.05 type I error level, two tail. All statistical analyses on secondary endpoints and on subgroups will be deemed to be exploratory in nature; for this reason, no correction of nominal significance levels for multiple inference will be applied.

\section{Safety/feasibility analysis, adverse events, and interruption of the trial}

A Safety Monitoring Committee (SMC) will conduct an analysis to assess the safety and feasibility of the IPERPE EP protocol after 30 patients complete the study, and the study will be continued only if both safety and feasibility are established. In this assessment, no other data besides the criteria for safety and feasibility will be unblinded. The study will be considered feasible if at least $80 \%$ of the patients randomized to the intervention group will correctly undergo the allocated treatment according to the study protocol. The study will be considered safe if no serious adverse events related to treatment will be detected in the intervention group while the allocated treatment is ongoing.

Serious adverse events (SAE) will be defined as any event that is fatal or immediately life threatening, permanently disabling, severely incapacitating, or requires prolonged hospitalization or that may jeopardize the patient and requires medical or surgical intervention to prevent one of the outcomes listed above. SAE will be considered related to the treatment if the attending physician believes that they might be directly related to enrollment in the clinical trial. In particular, SAE's will be considered to be study-related if the event follows a study procedure and could readily have been produced by the study procedure.

\section{Discussion}

This investigator-initiated, pragmatic, multicenter, prospective, interventional, open-label randomized clinical trial will assess the potential benefits for ARDS patients of a PEEP-setting strategy based on individual patients' response to PEEP in terms of alveolar recruitment and overdistension, as assessed by sequential measurement of EELV by the nitrogen washing-washout technique during a PEEP trial. Indeed, alveolar recruitability as a response to PEEP has wide inter-subject variability, and it is well established that PEEP can increase overdistension and thus static strain, while decreasing dynamic strain only if recruiting new alveolar units for tidal ventilations [36]. This variability in the response to PEEP between patients may explain the failure of several recent randomized trial to demonstrate a universal benefit from an overall high-PEEP strategy $[10,12,13]$, calling for the 
need of individualized strategies based on the actual measurement of recruitment and overdistension [20]. Such a strategy could be feasible with this bedside technique, which has been shown to reliably estimated lung's aerated volume [23-25] and may overcome the shortcomings of other recently proposed physiology-based PEEP titration techniques [9-14]. The potential implications of the results from this well-powered physiological multicenter trial could lead to an improvement in the knowledge on individualized PEEP titration in ARDS and may improve future ventilatory management of these patients.

\section{Trial status}

Protocol version 2.0, July 2019.

At the time of submission, the regulatory authorization has been obtained in the coordinating center. Enrolment has not yet started in the participating centers. First inclusion is planned in November 2022, and completion of recruitment is estimated to be completed in December 2024.

\section{Abbreviations}

ARDS: Acute respiratory distress syndrome; AOP: Airway opening pressure; BMI: Body mass index; CNS: Central nervous system; COPD: Chronic obstructive pulmonary disease; CRF: Case report form; CPIS: Modified clinical pulmonary infection score; $\mathrm{CSt}_{\mathrm{L}}$ : Static lung compliance; $\mathrm{Cst}_{\mathrm{RS}}$ : Static respiratory system compliance; $\mathrm{Crec}$ : Compliance of the recruited lung; $\mathrm{CT}$ scan: Computed tomography scan; $\mathrm{ECCO}_{2}-\mathrm{R}$ : Extracorporeal $\mathrm{CO}_{2}$ removal; ECMO: Extracorporeal membrane oxygenation; EELV: End-expiratory lung volume; EELV $\mathrm{REC}_{\text {: }}$ Recruited volume; ELISA: Enzyme-linked immunosorbent assay; $\mathrm{FiO}_{2}$ : Fraction of inspired oxygen; FRC: Functional residual capacity; FRC PEEPset: Aerated volume at set PEEP; GE Healthcare: General Electric Healthcare; ICU: Intensive care unit; ICUdeath: Mortality in ICU; IL: Interleukin; IL6AUC: Area under the curve of the interleukin- 6 serum blood cytokine concentration; NIV: Noninvasive ventilation; NMBA: Neuromuscular blockade; NYHA: New York Heart Association; PBW: Predicted body weight; $\mathrm{PaO}_{2}$ : Arterial oxygen partial pressure; PEEP: Positive end-expiratory pressure; $P_{\text {PEP }}$ : End-expiratory airway pressure; PEEP $_{E S}$ : End-expiratory esophageal pressure; PEEP : End-expiratory transpulmonary pressure; PEEP $\mathrm{ES}_{\text {,ZEEP }}$ : Endexpiratory esophageal pressure; Pplat AW: End-inspiratory airway pressure; Pplat Es: End-inspiratory esophageal pressure; Pplat ${ }_{E S O}$ : End-inspiratory

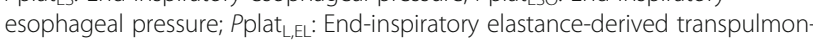
ary pressure; Pplat: Transpulmonary pressure; RASS: Richmond Agitation and Sedation Scale; Rec ZEEP-PEEP: Recruited volume from ZEEP to PEEP; R/ I: Recruitment-to-inflation ratio; SAPSII: Simplified Acute Physiology Score; SBT: Spontaneous breathing trial; SOFA: Sequential Organ Failure Assessment; $\mathrm{SpO}_{2}$ : Oxygen peripheral saturation; TNF: Tumor necrosis factor; $P_{\text {PLAT: }}$ Plateau pressure; VFD60: 60-day ventilation-free days; VILI: Ventilator-induced lung injury; $V_{T}$ : Tidal volume

\section{Supplementary Information}

The online version contains supplementary material available at https://doi. org/10.1186/s13063-021-05993-0.

\footnotetext{
Additional file 1: Participating centers.

Additional file 2: Organ failure definitions and scoring systems.

Additional file 3: Concomitant patient medical management.

Additional file 4: Scoring system for the primary endpoint.

Additional file 5: Sample size determination: assumptions and methodology.
}

\section{Acknowledgements}

Members of the IPERPEEP study group:

Antonio M. Dell'Anna ${ }^{1,2}$, Filippo Bongiovanni ${ }^{1,2}$, Gennaro De Pascale ${ }^{1,2}$, Daniele Natalini ${ }^{1,2}$, Gian Marco Anzellotti ${ }^{1,2}$, Giuseppe Bello ${ }^{1,2}$, Gabriele Pintaudi ${ }^{1,2}$, Salvatore Lucio Cutuli ${ }^{1,2}$, Melania Cesarano ${ }^{1,2}$, Luca Delle Cese ${ }^{1,2}$, Melania Cesarano ${ }^{1,2}$, Tommaso Rosà ${ }^{1,2}$, Eloisa Sofia Tanzarella ${ }^{1,2}$, Tony C. Morena ${ }^{1,2}$, Serena Silva ${ }^{1,2}$, Edoardo Piervincenzi ${ }^{1,2}$, Simone Carelli, ${ }^{1,2}$, Lorenzo Ball $^{10,11}$, Chiara Robba ${ }^{10}$, Iole Brunetti ${ }^{11}$, Gaetano Scaramuzzo ${ }^{6}$, Tania Stripoli ${ }^{12}$, Francesco Murgolo ${ }^{12}$, Rachele lannuzziello ${ }^{12}$, Giacomo Grasselli ${ }^{7}$, Tommaso Mauri ${ }^{7}$, Eugenio Garofalo ${ }^{13}$, Federico Longhini ${ }^{13}$, Eugenio Biamonte $^{13}$, Silvia Villa ${ }^{4,5}$, Fabio Rossitto ${ }^{3}$, Nicola Cornacchia ${ }^{3}$, Luigi Vetrugno ${ }^{3}$, Anita Orlando ${ }^{9}$, Eric Arisi ${ }^{9}$, Andrea Colombo ${ }^{9}$, Elisabetta Pierucci ${ }^{8}$, Giacinto Pizzilli ${ }^{8}$.

Department of Emergency, Intensive Care Medicine and Anesthesia, Fondazione Policlinico Universitario A. Gemelli IRCCS; Rome, Italy. Istituto di Anestesiologia e Rianimazione, Università Cattolica del Sacro Cuore Rome, Italy.

Department of Medical, Oral and Biotechnological Sciences, School of Medicine and Health Sciences, Section of Anesthesia, Analgesia, Perioperative and Intensive Care, SS. Annunziata Hospital, Gabriele d'Annunzio University of Chieti-Pescara, Chieti, Italy.

Department of Medicine and Surgery, University of Milan-Bicocca, Via Cadore 48, Monza, Italy.

Department of Emergency and Intensive Care, San Gerardo Hospital, Monza, Italy.

Department Morphology, Surgery and Experimental medicine, Anesthesia and Intensive care section, University of Ferrara, Azienda OspedalieraUniversitaria Sant'Anna, Ferrara, Italy.

Dipartimento di Anestesia, Rianimazione ed Emergenza-Urgenza, Fondazione IRCCS Ca' Granda Ospedale Maggiore Policlinico, Università degli studi di Milano, Milan, Italy.

Dipartimento di Scienze Mediche e Chirurgiche, Anesthesia and Critical Care Medicine, Policlinico di Sant'Orsola, Alma Mater Studiorum University of Bologna, Bologna, Italy.

Anesthesia and Intensive Care, Fondazione IRCCS Policlinico San Matteo, Università degli Studi di Pavia.

Department of Surgical Sciences and Integrated Diagnostics, DISC; University of Genoa, Genoa, Italy

Anesthesia and Intensive Care, San Martino Policlinico Hospital, IRCCS for Oncology and Neurosciences, Genoa, Italy.

Department of Emergency and Organ Transplant (D.E.T.O.), University of Bari Aldo Moro, Bari, Italy.

Anesthesia and Intensive Care Unit, Department of Medical and Surgical Sciences, University Hospital Mater Domini, Magna Graecia University,

Catanzaro, Italy.

CNR-IASI BioMatLab, Consiglio Nazionale delle Ricerche, Istituto di Analisi dei Sistemi ed Informatica, Laboratorio di Biomatematica (Italian National Research Council, Institute for System Analysis and Computer Science, Biomathematics Laboratory), Rome, Italy.

Department of Anesthesia and Intensive Care, Azienda Ospedaliera-Università di Padova, Padua, Italy.

Dipartimento di Medicina-DIMED, Università degli Studi di Padova, Via Giustiniani 2, 35128 Padova, Italy.

\section{Authors' contributions}

DLG and MA designed the study. SMM revised the first draft of the protocol, which was discussed and amended by all co-authors in live discussions. All the authors approved the final draft of the protocol and agreed on submitting it to Trials.

\section{Funding}

The study is supported by a grant provided by General Electric Healthcare, whose magnitude is in compliance with the requirements of the funding acceptable according to the Italian law on Non-Profit Studies ("Decreto 17 Dicembre 2004"). The study is investigator-initiated and the funder had no involvement in study design. The sponsor of the study is "Fondazione Policlinico Agostino Gemelli IRCCS."

\section{Availability of data and materials} Not applicable 


\section{Declarations}

\section{Ethics approval and consent to participate}

By the time of study start, the protocol will be approved by all Ethics Committees of involved centers. This study is conducted in accordance with the Declaration of Helsinki and was prospectively registered on at https:// clinicaltrials.gov with the trial identification number NCT04012073. Participants fulfilling the inclusion criteria or their legal representatives will sign an informed consent according to the Italian Law and ethics committee's recommendations. Withdrawal of consent may be initiated by the participant at any time during the trial.

\section{Consent for publication}

Not applicable

\section{Competing interests}

MA and DLG declare a research grant by General Electric healthcare for the conduction of this study. The authors declare that they have no competing interests.

\section{Author details}

'Department of Emergency, Intensive Care Medicine and Anesthesia, Fondazione Policlinico Universitario A. Gemelli IRCCS, L.go F. Vito, 00168 Rome, Italy. ${ }^{2}$ Istituto di Anestesiologia e Rianimazione, Università Cattolica del Sacro Cuore, L.go F. Vito, 00168 Rome, Italy. ${ }^{3}$ Department of Medical, Oral and Biotechnological Sciences, School of Medicine and Health Sciences, Section of Anesthesia, Analgesia, Perioperative and Intensive Care, SS. Annunziata Hospital, Gabriele d'Annunzio University of Chieti-Pescara, Chieti, Italy. ${ }^{4}$ Department of Medicine and Surgery, University of Milan-Bicocca, Via Cadore 48, Monza, Italy. ${ }^{5}$ Department of Emergency and Intensive Care, San Gerardo Hospital, Monza, Italy. ${ }^{6}$ Department Morphology, Surgery and Experimental medicine, Anesthesia and Intensive care section, University of Ferrara, Azienda Ospedaliera-Universitaria Sant'Anna, Ferrara, Italy. ${ }^{7}$ Dipartimento di Anestesia, Rianimazione ed Emergenza-Urgenza, Fondazione IRCCS Ca' Granda Ospedale Maggiore Policlinico, Università degli studi di Milano, Milan, Italy. ${ }^{8}$ Dipartimento di Scienze Mediche e Chirurgiche, Anesthesia and Critical Care Medicine, Policlinico di Sant'Orsola, Alma Mater Studiorum University of Bologna, Bologna, Italy. ${ }^{9}$ Anesthesia and Intensive Care, Fondazione IRCCS Policlinico San Matteo, Università degli Studi di Pavia, Pavia, Italy. ${ }^{10}$ Department of Surgical Sciences and Integrated Diagnostics, DISC, University of Genoa, Genoa, Italy. ${ }^{11}$ Anesthesia and Intensive Care, San Martino Policlinico Hospital, IRCCS for Oncology and Neurosciences, Genoa, Italy. ${ }^{12}$ Department of Emergency and Organ Transplant (D.E.T.O.), University of Bari Aldo Moro, Bari, Italy. ${ }^{13}$ Anesthesia and Intensive Care Unit, Department of Medical and Surgical Sciences, University Hospital Mater Domini, Magna Graecia University, Catanzaro, Italy. ${ }^{14} \mathrm{CNR}$-IASI BioMatLab, Consiglio Nazionale delle Ricerche, Istituto di Analisi dei Sistemi ed Informatica, Laboratorio di Biomatematica (Italian National Research Council, Institute for System Analysis and Computer Science, Biomathematics Laboratory), Rome, Italy. ${ }^{15}$ Department of Anesthesia and Intensive Care, Azienda Ospedaliera-Università di Padova, Padua, Italy. ${ }^{16}$ Dipartimento di Medicina-DIMED, Università degli Studi di Padova, Via Giustiniani 2, 35128 Padova, Italy.

\section{Received: 2 June 2021 Accepted: 30 December 2021}

Published online: 20 January 2022

\section{References}

1. Ranieri VM, Suter PM, Tortorella C, De Tullio R, Dayer JM, Brienza A, et al. Effect of mechanical ventilation on inflammatory mediators in patients with acute respiratory distress syndrome: a randomized controlled trial. JAMA. 1999;282:54-61 Available from: http://www.ncbi.nlm.nih.gov/pubmed/10404 912.

2. Amato MB, Barbas CS, Medeiros DM, Magaldi RB, Schettino GP, Lorenzi-Filho $\mathrm{G}$, et al. Effect of a protective-ventilation strategy on mortality in the acute respiratory distress syndrome. N Engl J Med. 1998;338(6):347-54. Available from:. https://doi.org/10.1056/NEJM199802053380602\%5Cnhttp://www.ncbi. nlm.nih.gov/pubmed/9449727.

3. Network ARDS, Brower RG, Matthay MA, Morris A, Schoenfeld D, Thompson $B T$, et al. Ventilation with lower tidal volumes as compared with traditional tidal volumes for acute lung injury and the acute respiratory distress syndrome. N Engl J Med. 2000;342:1301-8 Available from: http://www.ncbi. nlm.nih.gov/pubmed/10793162.

4. Amato MBP, Meade MO, Slutsky AS, Brochard L, EL V C, Schoenfeld DA, et al. Driving pressure and survival in the acute respiratory distress syndrome. N Engl J Med. 2015;372:747-55 Available from: http://www.ncbi. nlm.nih.gov/pubmed/25693014.

5. Grieco DL, Chen L, Dres M, Brochard L. Should we use driving pressure to set tidal volume. Curr Opin Crit Care. 2017;23(1):38-44. Available from: http://content.wkhealth.com/linkback/openurl?sid=WKPTLP:landingpage\&a $\mathrm{n}=00075198-900000000-99306$. https://doi.org/10.1097/MCC. 0000000000000377.

6. Goligher EC, Dres M, Patel BK, Sahetya SK, Beitler JR, Telias I, et al. Lung and diaphragm-protective ventilation. Am J Respir Crit Care Med. 2020; Available from: http://www.ncbi.nlm.nih.gov/pubmed/32516052.

7. Richard JC, Maggiore SM, Jonson B, Mancebo J, Lemaire F, Brochard L. Influence of tidal volume on alveolar recruitment. Respective role of PEEP and a recruitment maneuver. Am J Respir Crit Care Med. 2001;163:1609-13 Available from: http://www.ncbi.nlm.nih.gov/pubmed/11401882.

8. Maggiore SM, Jonson B, Richard JC, Jaber S, Lemaire F, Brochard L. Alveolar derecruitment at decremental positive end-expiratory pressure levels in acute lung injury: comparison with the lower inflection point, oxygenation, and compliance. Am J Respir Crit Care Med Am Thoracic Soc AJRCCM. 2001;164:795-801 Available from: http://www.ncbi.nlm.nih. gov/pubmed/11549535.

9. Grasso S, Terragni P, Mascia L, Fanelli V, Quintel M, Herrmann P, et al. Airway pressure-time curve profile (stress index) detects tidal recruitment/ hyperinflation in experimental acute lung injury. Crit Care Med. 2004;32(4): 1018-27. Available from: http://content.wkhealth.com/linkback/openurl?sid= WKPTLP:landing page\&an=00003246-200404000-00020. https://doi.org/10.1 097/01.CCM.0000120059.94009.AD.

10. Mercat A, Richard JM, Vielle B, Jaber S, Osman D, Diehl J-L, et al. Positive end-expiratory pressure setting in adults with acute lung injury and acute respiratory distress syndrome: a randomized controlled trial. JAMA. 2008;299: 646-55 Available from: http://www.ncbi.n/m.nih.gov/pubmed/18270353.

11. Kacmarek RM, Villar J, Sulemanji D, Montiel R, Ferrando C, Blanco J, et al. Open lung approach for the acute respiratory distress syndrome: a pilot, randomized controlled trial. Crit Care Med. 2016;44:32-42 Available from: http://content.wkhealth.com/linkback/openurl?sid=WKPTLP:landingpage\&a $\mathrm{n}=00003246-900000000-97080$.

12. Brower RG, Lanken PN, Maclntyre N, Matthay MA, Morris A, Ancukiewicz M, et al. Higher versus lower positive end-expiratory pressures in patients with the acute respiratory distress syndrome. N Engl J Med. 2004;351:327-36 Available from: http://www.ncbi.n/m.nih.gov/pubmed/15269312.

13. Meade MO, Cook DJ, Guyatt GH, Slutsky AS, Arabi YM, Cooper DJ, et al. Ventilation strategy using low tidal volumes, recruitment maneuvers, and high positive end-expiratory pressure for acute lung injury and acute respiratory distress syndrome: a randomized controlled trial. JAMA. 2008;299: 637-45 Available from: http://www.ncbi.n/m.nih.gov/pubmed/18270352.

14. Grasso S, Stripoli T, Sacchi M, Trerotoli P, Staffieri F, Franchini D, et al. Inhomogeneity of lung parenchyma during the open lung strategy: a computed tomography scan study. Am J Respir Crit Care Med. 2009;180: 415-23 Available from: http://www.ncbi.n/m.nih.gov/pubmed/19542479.

15. Writing Group for the Alveolar Recruitment for Acute Respiratory Distress Syndrome Trial (ART) Investigators, Cavalcanti AB, Suzumura ÉA, Laranjeira LN, Paisani D de M, Damiani LP, et al. Effect of lung recruitment and titrated positive end-expiratory pressure (PEEP) vs low PEEP on mortality in patients with acute respiratory distress syndrome: a randomized clinical trial. JAMA. 2017;318:1335-45 Available from: http://www.ncbi.n/m.nih.gov/pubmed/28973363.

16. Briel M, Meade M, Mercat A, Brower RG, Talmor D, Walter SD, et al. Higher vs lower positive end-expiratory pressure in patients with acute lung injury and acute respiratory distress syndrome: systematic review and metaanalysis. JAMA. 2010;303:865-73 Available from: http://www.ncbi.nlm.nih. gov/pubmed/20197533.

17. Gattinoni $L$, Caironi $P$, Cressoni M, Chiumello D, Ranieri VM, Quintel M, et al. Lung recruitment in patients with the acute respiratory distress syndrome. N Engl J Med, 86. 2006;354:1775 Available from: http://www.ncbi.nlm.nih. gov/pubmed/16641394.

18. Chiumello D, Cressoni M, Carlesso E, Caspani ML, Marino A, Gallazzi E, et al. Bedside selection of positive end-expiratory pressure in mild, moderate, and severe acute respiratory distress syndrome. Crit Care Med. 2014;42:252-64 Available from: http://www.ncbi.nlm.nih.gov/pubmed/24196193. 
19. Chen L, Del Sorbo L, Grieco DL, Junhasavasdikul D, Rittayamai N, Soliman I, et al. Potential for lung recruitment estimated by the recruitment-toinflation ratio in acute respiratory distress syndrome. a clinical trial. Am J Respir Crit Care Med. 2020;201:178-87 Available from: http://www.ncbi.nlm. nih.gov/pubmed/31577153

20. Spinelli E, Grieco DL, Mauri T. A personalized approach to the acute respiratory distress syndrome: recent advances and future challenges. J Thorac Dis. 2019;11:5619-25 Available from: http://jtd.amegroups.com/a rticle/view/33765/html.

21. Talmor D, Sarge T, Malhotra A, O'Donnell CR, Ritz R, Lisbon A, et al. Mechanical ventilation guided by esophageal pressure in acute lung injury. N Engl J Med. 2008;359:2095-104 Available from: http://www. pubmedcentral.nih.gov/articlerender.fcgi?artid=3969885\&tool= pmcentrez\&rendertype=abstract.

22. Beitler JR, Sarge T, Banner-Goodspeed VM, Gong MN, Cook D, Novack V, et al. Effect of titrating positive end-expiratory pressure (PEEP) with an esophageal pressure-guided strategy vs an empirical high PEEP-Fio2 strategy on death and days free from mechanical ventilation among patients with acute respiratory distress syndrome: A R. JAMA. 2019:1-12 Available from: http://www.ncbi.nlm.nih.gov/pubmed/30776290.

23. Dellamonica J, Lerolle N, Sargentini C, Beduneau G, Di Marco F, Mercat A, et al. PEEP-induced changes in lung volume in acute respiratory distress syndrome. Two methods to estimate alveolar recruitment. Intensive Care Med. 2011;37:1595-604 Available from: http://www.ncbi.nlm.nih.gov/ pubmed/21866369.

24. Chiumello D, Cressoni M, Chierichetti M, Tallarini F, Botticelli M, Berto V, et al. Nitrogen washout/washin, helium dilution and computed tomography in the assessment of end expiratory lung volume. Crit Care. 2008;12:R150 Available from: http://www.ncbi.nlm.nih.gov/pubmed/19046447.

25. Richard J-C, Pouzot C, Pinzón AM, González JST, Orkisz M, Neyran B, et al. Reliability of the nitrogen washin-washout technique to assess endexpiratory lung volume at variable PEEP and tidal volumes. Intensive care Med Exp. Springer. 2014;2:10 Available from: http://www.icm-experimental. com/content/2/1/10

26. ARDS Definition Task Force, Ranieri VM, Rubenfeld GD, Thompson BT, Ferguson ND, Caldwell $E$, et al. Acute respiratory distress syndrome: the Berlin Definition. JAMA. 2012;307:2526-33. Available from. https://doi.org/1 0.1001/jama.2012.5669.

27. Caironi P, Carlesso E, Cressoni M, Chiumello D, Moerer O, Chiurazzi C, et al. Lung recruitability is better estimated according to the Berlin definition of acute respiratory distress syndrome at standard $5 \mathrm{~cm} \mathrm{H} 2 \mathrm{O}$ rather than higher positive end-expiratory pressure. Crit Care Med. 2015;43:781-90 Available from: http://content.wkhealth.com/linkback/openurl?sid=WKPTLP: landingpage\&an=00003246-201504000-00008.

28. Pitoni S, D'Arrigo S, Grieco DL, Idone FA, Santantonio MT, Di Giannatale P, et al. Tidal volume lowering by instrumental dead space reduction in braininjured ARDS patients: effects on respiratory mechanics, gas exchange, and cerebral hemodynamics, vol. L. Available from. US: Neurocrit Care. Springer; 2020. https://doi.org/10.1007/s12028-020-00969-5.

29. Akoumianaki E, Maggiore SM, Valenza F, Bellani G, Jubran A, Loring SH, et al. The application of esophageal pressure measurement in patients with respiratory failure. Am J Respir Crit Care Me. 2014;189:520-31 Available from: http://www.ncbi.nlm.nih.gov/pubmed/24467647.

30. Grieco DL, Chen L, Brochard L. Transpulmonary pressure: importance and limits. Ann Transl Med. 2017;5:285 Available from: http://atm.amegroups. com/article/view/15710/15777.

31. Grieco DL, Anzellotti GM, Russo A, Bongiovanni F, Costantini B, D'Indinosante $M$, et al. Airway closure during surgical pneumoperitoneum in obese patients. Anesthesiology. 2019;131:1-16 Available from: http:// www.ncbi.n/m.nih.gov/pubmed/30882475.

32. Chen L, Del Sorbo L, Grieco DL, Shklar O, Junhasavasdikul D, Telias I, et al. Airway closure in acute respiratory distress syndrome: an underestimated and misinterpreted phenomenon. Am J Respir Crit Care Med. 2018;197:1326 Available from: http://www.ncbi.nlm.nih.gov/pubmed/28557528.

33. Grieco DL, Bongiovanni F, Chen L, Menga LS, Cutuli SL, Pintaudi G, et al. Respiratory physiology of COVID-19-induced respiratory failure compared to ARDS of other etiologies. Crit Care. 2020;24(1):529. Available from:. https:// doi.org/10.1186/s13054-020-03253-2.

34. Malatesta C, Mele F, Menga LS, Bello G, Grieco DL, Antonelli M. Airway closure and fiberoptic evidence of bronchial collapse during the acute respiratory distress syndrome. Intensive Care Med. Springer Berlin
Heidelberg. 2019:7-8. Available from. https://doi.org/10.1007/s00134-01905800-0.

35. Bein T, Weber-Carstens S, Goldmann A, Müller T, Staudinger T, Brederlau J, et al. Lower tidal volume strategy $(\approx 3 \mathrm{ml} / \mathrm{kg}$ ) combined with extracorporeal $\mathrm{CO} 2$ removal versus "conventional" protective ventilation $(6 \mathrm{ml} / \mathrm{kg})$ in severe ARDS: The prospective randomized Xtravent-study. Intensive Care Med. 2013;39(5):847-56. https://doi.org/10.1007/s00134-012-2787-6.

36. Grieco DL, Russo A, Romanò B, Anzellotti GM, Ciocchetti P, Torrini F, et al. Lung volumes, respiratory mechanics and dynamic strain during general anaesthesia. Br J Anaesth. 2018;121:1156-65 Available from: http://www. ncbi.nlm.nih.gov/pubmed/30336861.

\section{Publisher's Note}

Springer Nature remains neutral with regard to jurisdictional claims in published maps and institutional affiliations.
Ready to submit your research? Choose BMC and benefit from:

- fast, convenient online submission

- thorough peer review by experienced researchers in your field

- rapid publication on acceptance

- support for research data, including large and complex data types

- gold Open Access which fosters wider collaboration and increased citations

- maximum visibility for your research: over $100 \mathrm{M}$ website views per year

At BMC, research is always in progress.

Learn more biomedcentral.com/submissions 